\title{
SIMS Investigation of Oxygen in 3C-SiC on $\mathrm{Si}$
}

\author{
Jisheng Han $^{1}$, Sima Dimitrijev ${ }^{1}$, Fred Kong ${ }^{1}$, Philip Tanner ${ }^{1}$ and Armand Atanacio ${ }^{2}$ \\ ${ }^{1}$ Queensland Microtechnology Facility and Griffith School of Engineering, Griffith University, Nathan, Qld. 4111, Australia \\ ${ }^{2}$ Australian Nuclear Science and Technology Organization \\ Lucas Heights NSW 2234
}

Abstract - In this paper, we present and analyse Secondary Ion Mass Spectrometry (SIMS) measurements of oxygen concentration in $3 \mathrm{C} \mathrm{SiC}$ epitaxial layers on $\mathrm{Si}$. The concentration of oxygen determined by SIMS was as high as $10^{19}$ to $10^{20}$ atom $/ \mathrm{cm}^{3}$. Unlike silicon, oxygen can act as donor atoms in $\mathrm{SiC}$ with calculated ionization levels of $200 \mathrm{meV}$ [1]. It is generally believed that the main contribution of dopant concentration in the unintentionally doped $\mathrm{SiC}$ film is related to background nitrogen. Because of the high ionisation level, oxygen is not electrically active at room temperature. By measuring the conductivity of the films at higher temperatures, we extracted three donor energy levels: $E_{\mathrm{A} 1}=79 \mathrm{meV}, \mathbf{E}_{\mathrm{A} 2}=180 \mathrm{meV}$, and $E_{\mathrm{A} 3}$ $=350 \mathrm{meV}$. The activation energy of $180 \mathrm{meV}$ could be associated with the calculated ionization level for oxygen. Further analysis of the conductivity measurements at elevated temperatures will be performed to determine the electrically active donor concentration that is associated with the activation energy of 180 meV. Carbide

Keywords- Secondary Ion Mass Spectrometry, Cubic Silicon

\section{INTRODUCTION}

Cubic silicon carbide (3C-SiC) is considered to be excellent material for electronic devices operating at harsh environment because of its high thermal conductivity, high critical electric field, high saturation velocity and wide band gap $(2.2 \mathrm{eV})$. Using the chemical vapor deposition techniques, $3 \mathrm{C}-\mathrm{SiC}$ on silicon $(3 \mathrm{C}-\mathrm{SiC} / \mathrm{Si}$ ) wafers with large diameters can be achieved and at low cost [2], [3]. It is generally believed that the main contribution of dopant concentration in the unintentionally doped $\mathrm{SiC}$ film is related to background nitrogen. Recently, Eickoff et al. observed a deep donor level with ionization energy level of $195 \mathrm{meV}$ in undoped $3 \mathrm{C}-\mathrm{SiC}$ layers deposited on the SOI substrate from the temperature dependence of the carrier concentration. They attributed the origin of deep donor to the oxygen. The question of how the oxygen affect the electrical properties in 3C-SiC films has not been fully addressed. In this paper, we present and analyse Secondary Ion Mass Spectrometry (SIMS) measurements of oxygen concentration in $3 \mathrm{C}-\mathrm{SiC}$ epitaxial layers on silicon. We will also present measurements results and analyses of conductivity at different temperatures in the corresponding 3C-SiC films.

\section{EXPERIMENT}

The investigated $3 \mathrm{C}-\mathrm{SiC}$ films were prepared on silicon substrate at $1000^{\circ} \mathrm{C}$ deposition temperature using ALE (Atomic Layer Epitaxy) technique. Table I shows different
TABLE I. DIFFERENT GROWTH CONDITIONS OF 3C-SIC FILMS

\begin{tabular}{|c|c|c|}
\hline Sample No. & ALE films $\left(1000^{\circ} \mathrm{C}\right)$ & $\begin{array}{c}\text { SiC film } \\
\text { thickness }\end{array}$ \\
\hline $\mathrm{F} 1$ & $\begin{array}{c}\mathrm{SiH}_{4} \text { flow, pump out then } \mathrm{C}_{3} \mathrm{H}_{6} \\
\text { flow }\end{array}$ & $500 \mathrm{~nm}$ \\
\hline $\mathrm{F} 2$ & $\mathrm{SiH}_{4}$ and $\mathrm{C}_{2} \mathrm{H}_{2}$ flow together & $525 \mathrm{~nm}$ \\
\hline $\mathrm{F3}$ & $\begin{array}{c}\mathrm{SiH}_{4} \text { flow, pump out then } \mathrm{C}_{2} \mathrm{H}_{2} \\
\text { flow }\end{array}$ & $352 \mathrm{~nm}$ \\
\hline
\end{tabular}

growth conditions of the investigated 3C-SiC films. The growth rate of the investigated $3 \mathrm{C}-\mathrm{SiC}$ films are around 0.5 $0.8 \mathrm{~nm} /$ cycle. SIMS measurements were conducted at two different laboratories: Australian Nuclear Science and Technology Organisation (ANSTO) Sydney, and Evans Analytical Group (EAG), USA. Some issues remain with SIMS analysis such as nitrogen has very high ionisation potential $(14.5 \mathrm{eV})$, therefore ion yield is very low during SIMS analysis. Better ion yield is obtained from the cluster $\left(\mathrm{C}^{12} \mathrm{~N}^{14}\right)$. EAG labs used a very high ion beam current and claim to be able to determine accurate volume concentrations of $\mathrm{N}$ in $\mathrm{SiC}$ with lower limits of $2 \times 10^{15}$ atoms $/ \mathrm{cm}^{3}$. The SIMS experiments in EAG were performed using a CAMECA IMS$4 \mathrm{f}$ double focusing magnetic sector instruments equipped with oxygen and Cs primary ion beam sources, which is rastered over a square area. Beam current used in the analysis are 50 to 280nA. The experiments in ANSTO were performed using a CAMECA IMS-5f double focusing magnetic sector instruments equipped with oxygen and $\mathrm{Cs}$ primary ion beam sources. Beam current used in the analysis were 50 to $230 \mathrm{nA}$ and rastered over a square area $250 \times 250 \mu \mathrm{m}$. The electrical properties of the $3 \mathrm{C}$-SiC films were also investigated for the temperature range $300 \mathrm{~K}$ to $550 \mathrm{~K}$ using standard four-point probe technique without removal substrates. Ohmic contacts for four-point probe test structures were prepared by evaporation of $\mathrm{Ni}$.

\section{RESULT AND DisCUSSION}

Figure 1 shows the depth profiles of $\mathrm{C}, \mathrm{N}$, and $\mathrm{O}$ for different 3C-SiC samples using the $\mathrm{C}^{12} \mathrm{~N}^{14}$ cluster ion obtained from SIMS measurement at ANSTO. The result of sample F1 and F3 which were prepared with different epitaxy conditions of $\mathrm{SiC}$ on $\mathrm{Si}$ shows that high $\mathrm{O}$ counts were both detected which indicates that a high chemical concentration of oxygen exists in the samples. To confirm the high oxygen counts of the samples, an individual SIMS measurement was performed on 


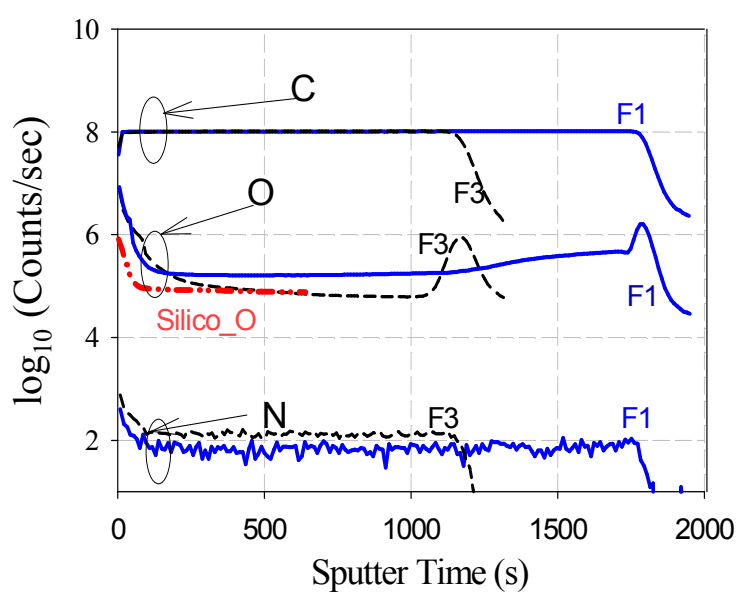

Fig 1: Negative ions concentration profile in 3C-SiC samples measured by SIMS at ANSTO.

a commercial Si substrate and included in Figure 1. The result shows that high oxygen counts were also detected which indicates that a high chemical concentration of oxygen exists in both the Si substrate and SiC. High levels of oxygen (up to $10^{20} / \mathrm{cm}^{3}$ ) in the sample F2 was detected by EAG SIMS measurement as shown in Figure 2. We have also extracted donor ionisation energies of the different samples from the conductivity measurement. The results are listed in Table II.

TABLE II. EXTRACTED ACTIVATION ENERGIES FOR DIFFERENT 3C-SiC FILMS

\begin{tabular}{|c|c|c|c|}
\hline Sample No. & $\mathrm{E}_{\mathrm{A} 1}(\mathrm{eV})$ & $\mathrm{E}_{\mathrm{A} 2}(\mathrm{eV})$ & $\mathrm{E}_{\mathrm{A} 3}(\mathrm{eV})$ \\
\hline $\boldsymbol{F 1}$ & 0.057 & 0.13 & \\
\hline $\boldsymbol{F} 2$ & 0.060 & 0.18 & \\
\hline $\boldsymbol{F 3}$ & 0.079 & 0.18 & 0.35 \\
\hline
\end{tabular}

Generally, all the films investigated exhibit a shallow donor ionization energy, $\mathrm{E}_{\mathrm{Al}}$, of less than $80 \mathrm{meV}$ from room temperature to $120^{\circ} \mathrm{C}$. The energy levels extracted are similar to nitrogen levels as determined by others [4] as Figure 3 shows the temperature dependence of the electrical conductivity of the sample.

In fact, $\mathrm{O}$ and $\mathrm{N}$ are two potential elements as donors to contribute to our measured conductivity. Both conductivity measurement and extracted activation energy indicate that $\mathrm{O}$ and $\mathrm{N}$ are two elements as donors. Although SIMS measurements show a higher count of $O$ in sample F1 compared to F3, the extracted activation energy of F1 indicates that nitrogen is still the main contribution in carrier concentration. However, the extracted activation energy of F1 starts to show as $0.180 \mathrm{eV}$ at higher $\left(>120^{\circ} \mathrm{C}\right)$ temperature which is close to the calculated ionization energy. This result

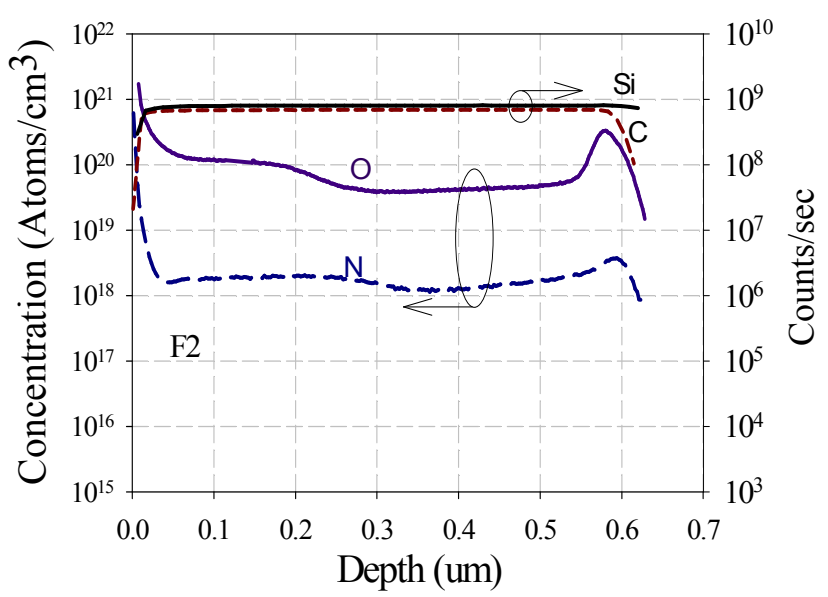

Fig 2: Negative ions concentration profile in 3C-SiC samples measured bv SIMS at EAG.

indicates that $\mathrm{O}$ is partly involved in the measured conductivity also.

Therefore, high chemical concentration oxygen does not necessarily mean that all the oxygen in the deposited film is electrically active. Electrical conductivity measurement shows that sample $\mathrm{F} 3$ exhibits another deeper donor level, $\mathrm{E}_{\mathrm{A} 3}=350$ $\mathrm{meV}$. The origin of this donor is not clear at the moment and it is likely due to structural defects at the $3 \mathrm{C}-\mathrm{SiC} / \mathrm{Si}$ interface. We also cannot rule out there is no parallel conduction due to the carrier from the silicon substrate at this high temperature. As for $\mathrm{Si}$, generally there is no significant change on temperature difference on the conductivity. Therefore, unlike $\mathrm{SiC}, \mathrm{O}$ does not play a major role in $\mathrm{Si}$ doping. Instead, $\mathrm{N}$ is a major donor contributor for the measured conductivity. The interstitial location of oxygen in the Si crystal might account for this observation - high chemical concentration oxygen and low electrical activity of oxygen.

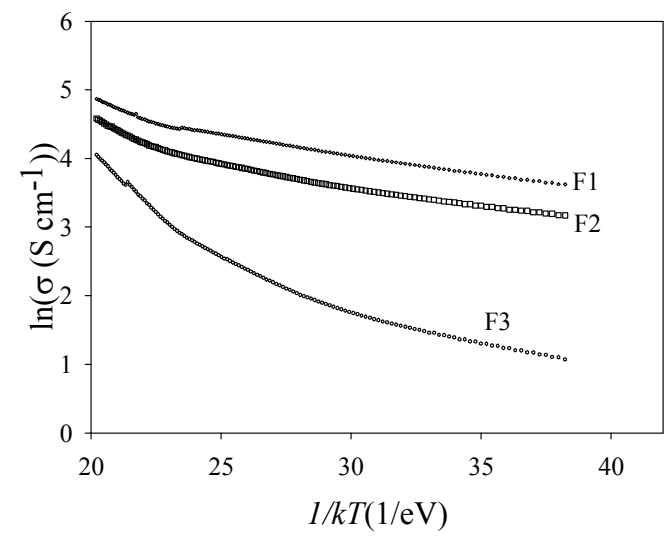

Fig 3: Measured conductivity versus temperature for different samples. 


\section{CONCLUSION}

Oxygen was observed in all samples analysed at ANSTO and EAG. High levels of oxygen (up to $10^{20} / \mathrm{cm}^{3}$ ) in the sample F2 was detected by EAG SIMS measurement. High oxygen counts were observed also in sample F1 and F3 in both the $\mathrm{SiC}$ and $\mathrm{Si}$ substrate by ANSTO SIMS measurement. The level in the $\mathrm{Si}$ was confirmed by measuring an unprocessed commercial Si wafer. Because high oxygen levels do not appear to be the main contributor to our measured electrical conductivity at room temperature and does not degrade crystal quality, it is not considered a major issue.

\section{ACKNOWLEDGMENT}

This work was supported by an Australian Institute of Nuclear Science and Engineering (AINSE) Grant and by Qs Semiconductors.

\section{REFERENCES}

[1] A. Gali, D. Heringer, P. Deak, Z. Hajnal, Th. Frauenheim, R. P. Devaty, and W. J. Choyke, Phys. Rev. B. 66, 125208 (2002).

[2] S. Nishino, J. A. Powell, and H.A. Will, Appl. Phys. Lett. 42, 460 (1983).

[3] H. Nagasawa and K. Yagi, Phys. Stat. Sol. (b) 202, 335 (1997).

[4] G. L. Harris, "Properties of Silicon Carbide", INSPEC, London, 1995 